\title{
Myocardial fatty acid oxidation in patients with impaired glucose tolerance
}

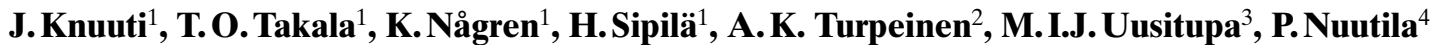 \\ ${ }^{1}$ Turku PET Centre, University of Turku and Turku University Central Hospital, Finland \\ ${ }^{2}$ Department of Clinical Nutrition, University of Kuopio and Kuopio University Hospital, Finland \\ ${ }^{3}$ Department of Medicine, University of Kuopio, Finland \\ ${ }^{4}$ Department of Medicine, University of Turku, Finland
}

\section{Abstract}

Aims/hypothesis. Fatty acids are an important source of energy in the myocardium. Abnormal myocardial fatty acid metabolism could contribute to the deterioration of cardiac function frequently observed in patients with Type II (non-insulin-dependent) diabetes mellitus. In our previous study, myocardial total uptake of non-esterified fatty acid (NEFA) was measured in patients with impaired glucose tolerance and found to be normal. This study aimed to investigate the subsequent metabolic steps and $\beta$-oxidation of NEFA.

Methods. A total of 6 men with impaired fasting glucose (age $50 \pm 2$ years, BMI $29 \pm 1 \mathrm{~kg} / \mathrm{m}^{2}$, means $\pm \mathrm{SEM})$ and 6 healthy men $(50 \pm 1$ years, $25 \pm 1 \mathrm{~kg} /$ $\mathrm{m}^{2}$ ) were studied in the fasting state. Myocardial blood flow was measured with $\left[{ }^{15} \mathrm{O}\right] \mathrm{H}_{2} \mathrm{O}$ and positron emission tomography and myocardial NEFA metabolism with $\left[{ }^{11} \mathrm{C}\right]$ palmitic acid.
Results. Myocardial blood flow was normal and not different between the impaired glucose tolerance and the control group ( $78 \pm 6 \mathrm{vs} 73 \pm 13 \mathrm{ml} / 100 \mathrm{~g} /$ min, NS). The $\left.{ }^{11} \mathrm{C}\right]$ palmitic acid uptake indices were similar between the groups $(10.4 \pm 0.5$ vs $11.2 \pm$ $0.8 \mathrm{ml} / 100 \mathrm{~g} / \mathrm{min}$, respectively, NS). The clearance of $\left[{ }^{11} \mathrm{C}\right]$-palmitate from the myocardium, an index of NEFA $\beta$-oxidation, was similar between the groups (half-times of activity $17.6 \pm 1.6$ vs $19.5 \pm 2.3 \mathrm{~min}$, respectively, NS)

Conclusion/interpretation. The results indicate that myocardial NEFA uptake and $\beta$-oxidation are not altered in patients with IGT. Thus, it is not likely that altered NEFA metabolism contributes to the deterioration of the cardiac function in patients with IGT or Type II diabetes. [Diabetologia (2001) 44: 184-187]

Keywords Impaired glucose tolerance, Type II diabetes, fatty acids, myocardial metabolism, $\left[{ }^{11} \mathrm{C}\right]$ palmitic acid, positron emission tomography.
On the basis of both experimental and human studies, it has been shown that diabetes could be associated with alterations in the myocardial glucose and the non-esterified fatty acid (NEFA) metabolism, which could further contribute to the deterioration of cardiac function [1]. The results of the recent studies with positron emission tomography (PET) have, however,

Received: 9 June 2000 and in revised form: 25 September 2000

Corresponding author: Prof. J. Knuuti MD, Turku PET Centre, University of Turku, P. O.Box 52, 20521 Turku, Finland Abbreviations: PET, positron emission tomography; SPET, single-photon emission tomography; $\left[{ }^{18} \mathrm{~F}\right] \mathrm{FTHA},\left[{ }^{18} \mathrm{~F}\right]$ fluoro-6thia-heptadecanoid acid; [ $\left.{ }^{123} \mathrm{I}\right] \mathrm{HDA},\left[{ }^{123} \mathrm{I}\right]$ heptadecanoid acid. shown that myocardial glucose uptake during euglycaemic hyperinsulinaemia both in patients with Type I (insulin-dependent) and II (non-insulin-dependent) diabetes is normal during controlled metabolic conditions (euglycaemic hyperinsulinaemia), confirming that the heart is not insulin-resistant in diabetes $[2,3]$.

Studies on myocardial NEFA metabolism are sparse. A study with $\left[{ }^{123} \mathrm{I}\right]$ heptadecanoid acid ([123I]HDA) and single-photon emission tomography (SPET) found myocardial NEFA uptake and $\beta$-oxidation to be reduced in patients with impaired glucose tolerance (IGT) [4]. Surprisingly, the same study found that NEFA metabolism was normal in patients with Type II diabetes. We recently measured the myocardial uptake of NEFA in patients with IGT 

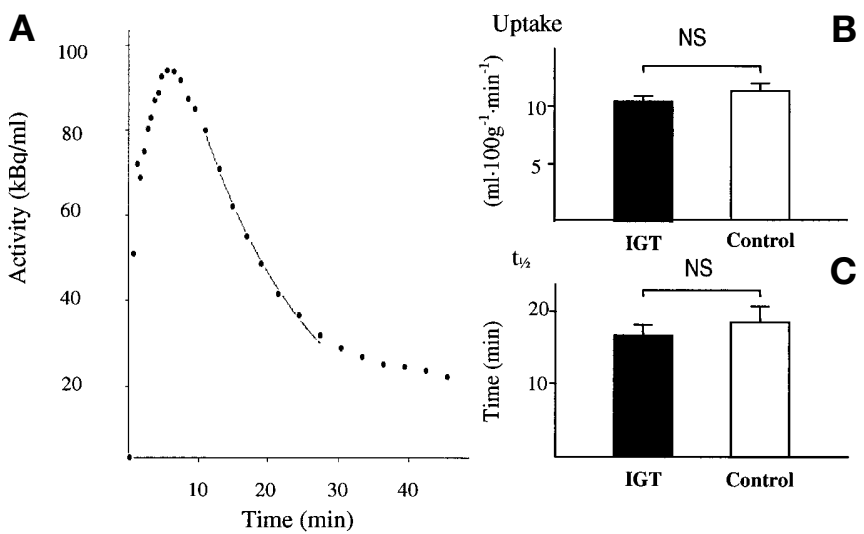

Fig. 1. An example of a biexponential curve fitted on the myocardial time-activity curve $(\mathbf{A})$ and myocardial $\left[{ }^{11} \mathrm{C}\right]$ palmitic acid uptake indices (B) and activity clearance halftimes $(\mathbf{C})$

with $14(\mathrm{R}, \mathrm{S})-\left[{ }^{18} \mathrm{~F}\right]$ fluoro-6-thia-heptadecanoid-acid ( $\left[{ }^{18} \mathrm{~F}\right]$ FTHA) and PET. No abnormalities in the total uptake was found in IGT patients studied in the fasting state but the skeletal muscle uptake of NEFA was impaired [5].

The fatty acid metabolism is complex. Because NEFA taken up by tissue will either enter oxidative metabolism or be incorporated into triglycerides, the possibility of defective $\beta$-oxidation cannot be completely excluded by the findings of our previous PET study with $\left[{ }^{18} \mathrm{~F}\right] \mathrm{FTHA}$. The $\left[{ }^{11} \mathrm{C}\right]$ palmitic acid is a proven and widely used tracer to assess myocardial FFA metabolism. Specifically, $\beta$-oxidation can be reliably measured with $\left[{ }^{11} \mathrm{C}\right]$ palmitate kinetics. This study included the same patients as in our previous PET study with $\left[{ }^{18} \mathrm{~F}\right] \mathrm{FTHA}$ [5] and re-examined then with $\left[{ }^{11} \mathrm{C}\right]$ palmitate. Our aim was to examine whether myocardial NEFA $\beta$-oxidation, in addition to NEFA uptake, is altered in IGT.

\section{Subjects and methods}

Subjects. A total of 6 men with IGT (age $50 \pm 2$ years) as defined by the criteria of the World Health Organisation (WHO) were studied. Another 6 healthy, normal-weight men matched for age served as control subjects. None of the subjects had a history of any cardiac illness. The subjects had participated in our previous PET study, in which we measured myocardial and skeletal muscle NEFA uptake with $\left[{ }^{18} \mathrm{~F}\right]$ FTHA [5]. The study was approved by the local ethics committee and all subjects gave their written and informed consent.

Study design. All subjects were studied after a 12 to $15 \mathrm{~h}$ fast in order to achieve high NEFA concentrations and enhance NEFA utilization. Myocardial blood flow was measured with $\left[{ }^{15} \mathrm{O}\right] \mathrm{H}_{2} \mathrm{O}$ and PET. Myocardial NEFA oxidation was measured with $\left[{ }^{11} \mathrm{C}\right]$ palmitic acid. The mean doses of $\left[{ }^{15} \mathrm{O}\right] \mathrm{H}_{2} \mathrm{O}$ and $\left[{ }^{11} \mathrm{C}\right]$ palmitic acid were $1.59 \pm 0.02 \mathrm{GBq}$ and $730 \pm 10$ MBq. Serum NEFA, glucose, insulin and plasma lactate concentrations were determined. Electrocardiogram, heart rate and blood pressure were monitored throughout the study.
Production of $\left[{ }^{15} \mathrm{O}\right] \mathrm{H}_{2} \mathrm{O}$ and $\left[{ }^{11} \mathrm{C}\right]$ palmitic acid. We produced ${ }^{15} \mathrm{O}$-labeled water using dialysis techniques in a continuously working water module. The $\left[{ }^{11} \mathrm{C}\right]$ palmitic acid was produced according to a method published previously [6]. The product was obtained in higher than $98 \%$ in radiochemical purity.

Image acquisition, processing and analysis. An ECAT 931/ 08-12 tomograph (Siemens/CTI, Knoxville, Tenn., USA) was used. All data were corrected for deadtime, decay and photon attenuation. The median root prior (MRP) reconstruction method was used.

Regions of interest (ROIs) were placed on the left ventricular myocardium on 4 cross-sectional slices to lateral, anterior and septal regions. The blood flow was calculated according to a method using a single compartment model [7]. A $\left[{ }^{11} \mathrm{C}\right]$ palmitic acid uptake index in myocardium was calculated by dividing the myocardial activity at $7.5 \mathrm{~min}$ with the integral of the metabolite corrected plasma time-activity curve. The NEFA uptake indices were calculated by multiplying the $\left[{ }^{11} \mathrm{C}\right]$ palmitic acid uptake index with the serum NEFA concentration. To measure $\left[{ }^{11} \mathrm{C}\right]$ palmitic acid $\beta$-oxidation, a biexponential curve was fitted on the early part (11-27.5 min) of the down-sloping phase of the time-activity curve (Fig.1) and the ${ }^{11} \mathrm{C}$-activity clearance at half-time was calculated. The non-metabolized fraction of $\left[{ }^{11} \mathrm{C}\right]$ palmitic acid in blood was measured by separating the $\left[{ }^{11} \mathrm{C}\right] \mathrm{CO}_{2}$ from blood samples.

Analytical procedures. Serum NEFAs were measured using an enzymatic method (Wako Chemicals, Neuss, Germany), serum free insulin using a double antibody radioimmunoassay (Pharmacia, Uppsala, Sweden) and glycated haemoglobin with fast protein liquid chromatography (Pharmacia, Uppsala, Sweden). Standard methods were used to measure serum glucose, lactate, total cholesterol, HDL-cholesterol and triglyceride concentrations.

Statistical analysis. Data were analysed using the software SPSS for Windows (version 6.0; SPSS, Ill., Chicago, USA). After the normal distribution of the variables had been checked a two-tailed Student's $t$-test and an analysis of variance and covariance were carried out to study the differences between the groups. All results are expressed as means \pm SEM. A $p$ value of less than 0.05 was considered to be statistically significant.

\section{Results}

Clinical characteristics, substrate concentrations and haemodynamic parameters during the study. Subjects with IGT were more obese than the control subjects (Table 1). Fasting serum glucose $(p<0.01)$, insulin $(p<0.01)$ and triglyceride concentrations $(p<0.05)$ were significantly higher in the IGT group than in the control group, whereas serum NEFA concentrations and serum total, LDL and HDL cholesterol concentrations were similar in the groups. Systolic and diastolic blood pressure were higher in IGT subjects but the double product was not significantly different.

Myocardial blood flow. Myocardial blood flow values were similar in the IGT group and the control group $\left(78 \pm 6\right.$ vs $\left.73 \pm 13 \mathrm{ml} \cdot 100 \mathrm{~g}^{-1} \cdot \mathrm{min}^{-1}, \mathrm{NS}\right)$. The flow 
Table 1. Clinical and metabolic characteristics of the subjects

\begin{tabular}{lcc}
\hline & $\begin{array}{l}\text { IGT subjects } \\
(n=6)\end{array}$ & $\begin{array}{l}\text { Control } \\
\text { subjects } \\
(n=6)\end{array}$ \\
\hline Age (years) & $50 \pm 2$ & $50 \pm 1$ \\
BMI (kg/m $\left.{ }^{2}\right)$ & $29 \pm 1^{\mathrm{a}}$ & $25 \pm 1$ \\
S-Glucose (mmol/l) & $5.8 \pm 0.2^{\mathrm{b}}$ & $4.8 \pm 0.2$ \\
S-Insulin $(\mathrm{mU} / \mathrm{l})$ & $9.8 \pm 2.2^{\mathrm{a}}$ & $4.0 \pm 0.3$ \\
P-Lactate $(\mathrm{mmol} / \mathrm{l})$ & $0.7 \pm 0.1$ & $0.6 \pm 0.1$ \\
S-FFA (mmol/l) & $0.60 \pm 0.03$ & $0.50 \pm 0.04$ \\
S-Triglycerides $(\mathrm{mmol} / \mathrm{l})$ & $1.1 \pm 0.2^{\mathrm{a}}$ & $0.5 \pm 0.1$ \\
S-Cholesterol (mmol/l) & $4.8 \pm 0.3$ & $4.8 \pm 0.4$ \\
S-LDL-Cholesterol $(\mathrm{mmol} / \mathrm{l})$ & $3.1 \pm 0.2$ & $3.0 \pm 0.3$ \\
S-HDL-Cholesterol $(\mathrm{mmol} / \mathrm{l})$ & $1.23 \pm 0.13$ & $1.45 \pm 0.12$ \\
Systolic blood pressure $(\mathrm{mmHg})$ & $133 \pm 3^{\mathrm{a}}$ & $120 \pm 5$ \\
Diastolic blood pressure $(\mathrm{mmHg})$ & $82 \pm 2^{\mathrm{a}}$ & $71 \pm 3$ \\
Heart rate $(1 / \mathrm{min})$ & $63 \pm 2$ & $57 \pm 4$ \\
Double product $\left(\mathrm{mmHG} \times \mathrm{min}^{-1}\right)$ & $8400 \pm 500$ & $6900 \pm 700$ \\
\hline Data are means $\pm \mathrm{SEM}$ & &
\end{tabular}

Data are means \pm SEM

${ }^{\mathrm{a}} p<0.05$

${ }^{\mathrm{b}} p<0.01$

results were only available for 4 of the IGT subjects as PET data on two subjects was lost due to technical problems.

Myocardial $\quad{ }^{11}$ Clpalmitic acid kinetics. The $\left[{ }^{11} \mathrm{C}\right]$ palmitic acid uptake indices were similar between the IGT group and the control group $\left(10.4 \pm 0.5\right.$ vs $\left.11.2 \pm 0.8 \mathrm{ml} \cdot 100 \mathrm{~g}^{-1} \cdot \mathrm{min}^{-1}, \mathrm{NS}\right)$. The NEFA uptake indices were also similar between the groups $\left(5.7 \pm 0.6\right.$ vs $6.2 \pm 0.3 \mu \mathrm{mol} \cdot 100 \mathrm{~g}^{-1} \cdot \mathrm{min}^{-1}$, NS). There was no statistically significant difference in radioactivity clearance half-times between the groups $(17.6 \pm 1.6$ vs $19.5 \pm 2.3 \mathrm{~min}$, respectively, NS) (Fig.1). The NEFA uptake index correlated with the blood flow in the pooled population $(r=0.63$, $p=0.04$ ) but not in the groups taken separately. In the covariance analysis with the rate-pressure-product, blood flow, BMI and triglyceride concentration as covariates the $\left.{ }^{[1} \mathrm{C}\right]$ palmitic acid and NEFA uptake indices were similar between the groups.

\section{Discussion}

The present study showed that myocardial NEFA uptake and $\beta$-oxidation especially are not significantly altered in subjects with IGT in the fasting state. This finding is in accordance with our previous $\left[{ }^{18} \mathrm{~F}\right]$ FTHA PET study suggesting that myocardial NEFA uptake is not changed in IGT [5] but this study extends these findings to the oxidative metabolism.

Only a few studies have been carried out on myocardial NEFA metabolism in Type II diabetic or IGT subjects and the results have been controversial. Myocardial NEFA uptake has been observed to be reduced over $30 \%$ and $\beta$-oxidation over $50 \%$ in subjects with IGT in a study with SPET and $\left[{ }^{123} \mathrm{I}\right] \mathrm{HDA}$.
The defect was not detected, however, in patients with Type II diabetes in that study [4]. The $\left[{ }^{123} I\right]$ heptadecanoic acid is known to be of limitated use for the quantification of myocardial NEFA $\beta$-oxidation when compared with $\left[{ }^{11} \mathrm{C}\right]$ palmitic acid [8] and those limitations could have been the reason for the finding of reduced myocardial NEFA uptake and $\beta$-oxidation in IGT in that study.

The rapid clearance half-times of both the IGT group and the control group (17.6 \pm 1.6 and $19.5 \pm 2.3 \mathrm{~min}$ ) were similar to previously measured halftimes in healthy subjects $(19.1 \pm 3.2 \mathrm{~min}$ and $17.3 \mathrm{~min} \pm 0.6 \mathrm{~min})[9,10]$. In previous studies, the fraction of $\left[{ }^{11} \mathrm{C}\right]$ palmitic acid rapidly oxidized and the fraction going to other intracellular lipid pools has been estimated. The myocardial ${ }^{11} \mathrm{C}$-activity curve was also biexponential in this study, but the fraction of $\left[{ }^{11} \mathrm{C}\right]$ palmitic acid going to other intracellular lipid pools was not estimated due to limited scanning time. Since neither NEFA oxidation nor total uptake changed, however, it can be indirectly estimated that the incorporation of NEFA into triglycerides is also unchanged in patients with IGT.

The $\left[{ }^{11} \mathrm{C}\right]$ palmitic acid uptake indices obtained in the present study were similar to the fractional uptake of the other FFA tracer, $\left[{ }^{18} \mathrm{~F}\right] \mathrm{FTHA}$, observed in the same subjects in the previous PET study $\left(\left[{ }^{11} \mathrm{C}\right]\right.$ palmitic acid: $10.4 \pm 0.5$ vs $11.2 \pm 0.8 \mathrm{ml} \cdot 100 \mathrm{~g}^{-1} \cdot \mathrm{min}^{-1}$, $\left[{ }^{18}\right.$ F]FTHA: $11 \pm 1$ vs $10 \pm 1 \mathrm{ml} \cdot 100 \mathrm{~g}^{-1} \cdot \mathrm{min}^{-1}$, IGT vs control group) [5]. Furthermore, the estimated NEFA uptake indices obtained in this study were concordant with the NEFA uptake values observed in our previous study $\left(\left[{ }^{11} \mathrm{C}\right]\right.$ palmitic acid: $5.7 \pm 0.6$ vs $6.2 \pm 0.3 \mu \mathrm{mol} \cdot 100 \mathrm{~g}^{-1} \cdot \mathrm{min}^{-1},\left[{ }^{18} \mathrm{~F}\right]$ FTHA: $5.6 \pm 0.4$ vs $\left.5.2 \pm 0.4 \mu \mathrm{mol} \cdot 100 \mathrm{~g}^{-1} \cdot \mathrm{min}^{-1}\right)$. In addition, as can be seen from the fact that substrate availability, an important factor for NEFA uptake, was similar in the groups since myocardial perfusion and serum FFA concentrations were similar in the groups. The results of this study reflect, however, only the conditions of subjects in the fasting state and at rest.

In conclusion, similar myocardial FFA $\beta$-oxidation between the IGT group and control subjects in this study argues against the hypothesis that altered FFA metabolism contributes to the deterioration of cardiac functions frequently observed in patients with Type II diabetes.

Acknowledgements. This study was supported by grants from the Finnish Foundation of Cardiovascular Research; the Academy of Finland, Helsinki; the Turku University Central Hospital and Kuopio University Hospital.

\section{References}

1. Rodrigues B, Cam MC, McNeill JH (1995) Myocardial substrate metabolism: implications for diabetic cardiomyopathy. J Mol Cell Cardiol 27: 169-179 
2. Mäki M, Nuutila P, Härkönen R et al. (1997) Myocardial glucose uptake in patients with NIDDM and stable coronary artery disease. Diabetes 46: 1491-1496

3. Nuutila P, Knuuti J, Ruotsalainen U et al. (1993) Insulin resistance is localized to skeletal but not heart muscle in type I diabetes. Am J Physiol 264: E756-E762

4. Turpeinen AK, Kuikka JT, Vanninen E, Uusitupa MIJ (1997) Abnormal myocardial kinetics of 123I-heptadecanoic acid in subjects with abnormal glucose tolerance. Diabetologia 40: 541-549

5. Turpeinen AK, Takala TO, Nuutila P et al. (1999) Impaired free fatty acid uptake in skeletal muscle but not in myocardium in patients with impaired glucose tolerance. Diabetes 48: 1245-1250

6. Padgett HC, Robinson GD, Barrio JR (1982) [1-11C]Palmitic acid: improved radiopharmaceutical preparation. Int $\mathbf{J}$ Appl Radiat Isot 33: 1471-1472
7. Iida H, Kanno I, Takahashi A et al. (1988) Measurement of absolute myocardial blood flow with $\mathrm{H}_{2}{ }^{15} \mathrm{O}$ and dynamic positron emission tomography. Circulation 78: 104-115

8. Schön HR (1986) I-123 heptadecanoid acid value and limitations in comparison with $\mathrm{C}-11$ palmitic acid. Eur J Nucl Med 12: S16-S19

9. Schelbert HR, Henze E, Sochor H (1986) Effects of substrate availability on myocardial C-11 palmitic acid kinetics by positron emission tomography in normal subjects and patients with ventricular dysfunction. Am Heart J 111: 1055-1064

10. Tamaki N, Kawamoto M, Takahashi N et al. (1993) Assesment of myocardial fatty acid metabolism with positron emission tomography at rest and during dobutamine infusion in patients with coronary heart disease. Am Heart J 125: 702-710 